Original Article

\title{
IMPACT OF ACNE VULGARIS ON A PERSON'S QUALITY OF LIFE AND IT'S CORRELATION WITH THE CLINICAL SEVERITY PRE AND POST-DRUG THERAPY
}

\author{
SWOPNA PHUKAN 1 , SAHELI DAS ${ }^{*}$ \\ 1Department of Pharmacology, Diphu Medical College, Diphu 782462, ${ }^{2}$ Department of Pharmacology, Gauhati Medical College, Guwahati \\ 781032 \\ Email: sahelidas037@gmail.com
}

Received: 28 Sep 2021, Revised and Accepted: 11 Nov 2021

\begin{abstract}
Objective: The aim of the study is to assess the therapeutic efficacy of drugs used in acne vulgaris by measuring the severity of acne using the Global Acne Grading System score (GAGS) and Cardiff Acne Disability Index (CADI) questionnaire score pre and post-drug therapy.

Methods: The present study was conducted in the Department of Dermatology after getting approval from the Institutional Ethics Committee (No MC/190/2007/Pt1/MAR-2019/PG/123) dated 10/04/2019. It was an observational study for a period of $1 \mathrm{y} .172$ patients were enrolled in the study. Patients were divided into 4 grades depending on their clinical manifestation. The severity of acne vulgaris and the quality of life were measured using the GAGS scale and the CADI questionnaire, respectively at the first visit and at the follow-up visit in all the grades of acne vulgaris.
\end{abstract} A correlation was done between the GAGS and the CADI score at the follow-up visit in all grades of acne.

Results: It was observed that the GAGS score and the CADI score was significantly improved at the F/U visit ( $\mathrm{p}<0.05$ ) as compared to baseline in all the 4 grades of acne. A correlation between GAGS score and QoL using CADI scale was done using Pearson Parametric Correlation Test. In none of the groups, the correlation was significant $(\mathrm{p}>0.05)$.

Conclusion: We can conclude from our study that following treatment with drugs, the clinical severity of acne decreased and there was also a significant improvement in the quality of life of patients.

Keywords: Acne vulgaris, GAGS score, Quality of life, CADI score

(C) 2022 The Authors. Published by Innovare Academic Sciences Pvt Ltd. This is an open access article under the CC BY license (https://creativecommons.org/licenses/by/4.0/) DOI: https://dx.doi.org/10.22159/ijpps.2022v14i1.43256. Journal homepage: https://innovareacademics.in/journals/index.php/ijpps.

\section{INTRODUCTION}

Skin is the largest organ of the body. Acne vulgaris is the most common skin disorder affecting more than $80 \%$ of teenagers. It is a chronic inflammatory disease of the pilosebaceous glands and is characterized by the formation of blackheads (open comedones), whiteheads (closed comedones), papules, pustules, nodules, cysts and scars [1]. Certain drugs such as steroids, anticonvulsants, OCP, endocrine disorders may also cause acne. Prevalence among the Western population is higher as they consume diet rich in high glycemic index which is responsible for the elevation of IGF-1 levels in the body [2-4].

Individuals suffering from disorders like polycystic ovarian disease (PCOD), hyperandrogenism, hypercortisolism and precocious puberty are at increased risk for the development of acne. Mild cases of acne have been reported in some neonates also because of stimulation of follicles by adrenal androgen [5].

There are different methods for measuring the severity of acne vulgaris, which includes simple grading, lesion counting and other methods such as photography, video microscopy. The first grading system was done by Pillsbury et al. [6]. Doshi et al. [7] in the year 1997 devised the Global Acne Grading System (GAGS).

Acne can also have a huge psychosocial effect on a person leading to loss of self-esteem, social isolation and major depression $[8,9]$. Vocational, academic and social activities are impaired, especially in severe grades of acne. Quality of life (QoL) of an individual is grossly affected. QoL is an indicator of how an individual experience and evaluate their own lives. In our study, we have used the Cardiff Acne Disability Index (CADI) [10] to assess the impact of acne on the QoL.

\section{MATERIALS AND METHODS}

Patients clinically diagnosed with Grade I to Grade IV Acne vulgaris and more than $12 \mathrm{y}$ of age of either gender were included and pregnant and lactating mothers were excluded from the study.
This was an observational study conducted in the outpatient department of Dermatology, Gauhati Medical College, Guwahati for a period of $1 \mathrm{y}$ from June, 2019 to May, 2020. A total of 172 patients were recruited into the study. The study protocol was approved by the Institutional Ethics Committee (IEC) (190/2007/Pt-11/MAR2019/Pcr/123). Written informed consent was taken from all the patients. Acne severity was calculated using the GAGS score and the CADI questionnaire at the baseline and the follow up visit. The CADI questionnaire is self-explanatory and validated. Permission from the author was taken. It consists of five questions and each question is scored from 0-3. The total scoring is from 0-15. Higher score indicates more impact on the quality of life.

The data was recorded in Microsoft Excel Worksheet version 2013. The statistical evaluation was done using Graph Pad demo version 4.00 [11]. GAGS score and CADI score was expressed as mean \pm SEM. intragroup comparison of GAGS score and quality of life using CADI score was done between baseline and at $\mathrm{F} / \mathrm{U}$ visit at the end of $4 \mathrm{w}$ by paired $t$-test in all the four grades of acne. $p<0.05$ was considered to be statistically significant. A correlation between GAGS score and QoL using CADI scale was done using Pearson Parametric Correlation Test.

\section{RESULTS}

A total number of 172 patients presenting with acne vulgaris were included in the study.

The number of patients in the study was divided into four grades according to the classification given by Tutakne $M$ et al. [12].

Grade I acne vulgaris-30 patients

Grade II acne vulgaris-96 patients

Grade III acne vulgaris-34 patients

Grade IV acne vulgaris-12 patients 
Doshi et al. [7] devised the Global Acne Grading System (GAGS).

In this system, a factor is assigned depending on the location of acne:

Forehead-2, Right cheek-2, Left cheek-2, Nose-1, Chin-1, Chest and upper back-3

Depending on the type of lesions, a score is assigned (No lesions $=0$, Comedones $=1$, Papules $=2$, Pustules $=3$, Nodules $=4$ ).

The factor is multiplied by the type of lesion for each area and the total GAGS score is obtained for an individual. The mean GAGS score in all the grades of acne are calculated and expressed as mean \pm SEM

I. Assessment of the therapeutic efficacy of drugs by using the Global Acne Grading Scale (GAGS) at the baseline visit and the follow up visit at the end of $4 \mathrm{w}$ of therapy in all the four grades of acne vulgaris as shown in fig 1:

\section{Analysis of efficacy in grade I}

The mean value of GAGS score at baseline was $5.93 \pm 0.45$, while it was $1.50 \pm 0.31$ at the follow-up visit. As shown in fig 1 , there was a significant reduction at the follow-up visit at the end of $4 \mathrm{w}$ $(\mathrm{p}<0.001)$.

\section{Analysis of efficacy in grade II}

The mean value of GAGS score at baseline was $20 \pm 0.32$ while it was $11.51 \pm 0.33$ at the follow up visit. There was a significant reduction at the follow up visit at the end of $4 \mathrm{w}(\mathrm{p}<0.001)$.

\section{Analysis of efficacy in grade III}

The mean value of GAGS score at baseline was $31.03 \pm 0.39$, while it was $17.94 \pm 0.59$ at the follow up visit. We observe that there was a significant reduction of GAGS score at the follow-up visit at the end of $4 \mathrm{w}(\mathrm{p}<0.001)$.

\section{Analysis of efficacy in grade IV}

The mean value of GAGS score at baseline was $37.16 \pm 0.80$, while it was $23.91 \pm 1.60$ at the follow-up visit. There was a significant reduction of GAGS score $(\mathrm{p}<0.001)$ at the follow-up visit at the end of $4 \mathrm{w}$.

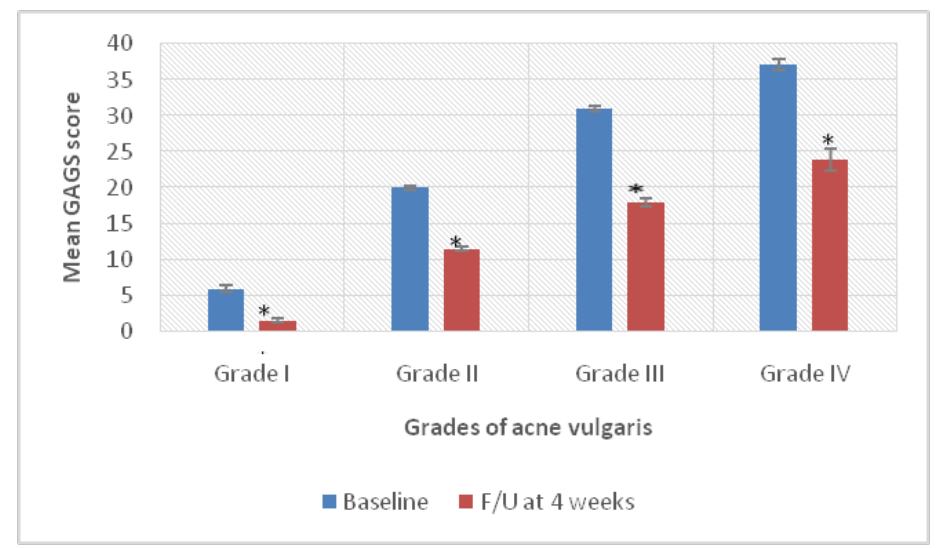

Fig. 1: Comparison of GAGS score at baseline and follow up at $4 \mathrm{w}$ in different grades of acne vulgaris, Mean GAGS score expressed as mean \pm SEM

Grade I-30 patients, Grade II-96 patients, Grade III-34 patients, Grade IV-12 patients (Grade I Baseline-5.93 \pm 0.45 Follow up$1.50 \pm 0.31$, Grade II Baseline-20 \pm 0.32 Follow up-11.51 \pm 0.33 , Grade III Baseline-31.03 \pm 0.39 Follow up-17.94 \pm 0.59 , Grade IV Baseline$37.16 \pm 0.80$ Follow up-23.91 \pm 1.60 )

\section{${ }^{*} p<0.001$ at follow up as compared to baseline}

II. Analysis of quality of life using Cardiff Acne Disability Index (CADI) questionnaire at the baseline and follow up visit as shown in fig. 2 :

Grade I: The mean CADI score at baseline was $3.93 \pm 0.36$ and at the end of $4 \mathrm{w}$ at the follow up visit was $1.90 \pm 0.24$. There was a significant reduction $(\mathrm{p}<0.001)$ in the CADI score at the end of $4 \mathrm{w}$ as shown in fig. 2.

Grade II: The mean CADI score at baseline was $7.06 \pm 0.18$ and at the end of $4 \mathrm{w}$ was $3.05 \pm 0.17$. There was a significant reduction $(\mathrm{p}<0.001)$ in the CADI score at the end of $4 \mathrm{w}$.

Grade III: The mean CADI score at baseline was $11.91 \pm 0.36$ and at the follow up visit was $6.38 \pm 0.38$. $(\mathrm{p}<0.001)$

Grade IV: The mean CADI score at baseline was $13.16 \pm 0.52$ and at the end of $4 \mathrm{w}$ at the follow up visit was $9.33 \pm 1.08$. The reduction was significant $(\mathrm{p}<0.001)$.

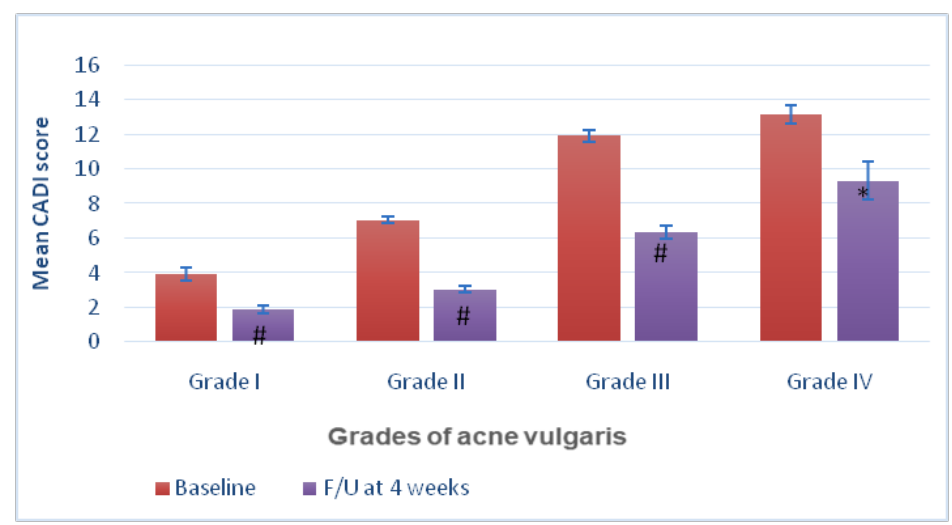

Fig. 2: Comparison of CADI score at baseline and follow up at $4 \mathrm{w}$ in different grades of acne vulgaris, mean CADI score expressed as mean \pm SEM 
Grade I-30 patients, Grade II-96 patients, Grade III-34 patients, Grade IV-12 patients

(Grade I Baseline-3.93 \pm 0.36 Follow up-1.90 \pm 0.24 , Grade II Baseline7.06 \pm 0.18 Follow up- $3.05 \pm 0.17$, Grade III Baseline- $11.91 \pm 0.36$ Follow up-6.38 \pm 0.38 , Grade IV Baseline-13.16 \pm 0.52 Follow up-9.33 \pm 1.08 )

${ }^{*} p<0.05$ at follow up as compared to baseline

$\# p<0.001$ at follow up as compared to baseline

III. Correlation between GAGS score and CADI score at the follow up visit at the end of four weeks for each grade of acne vulgaris (fig. 3, 4, 5, 6).

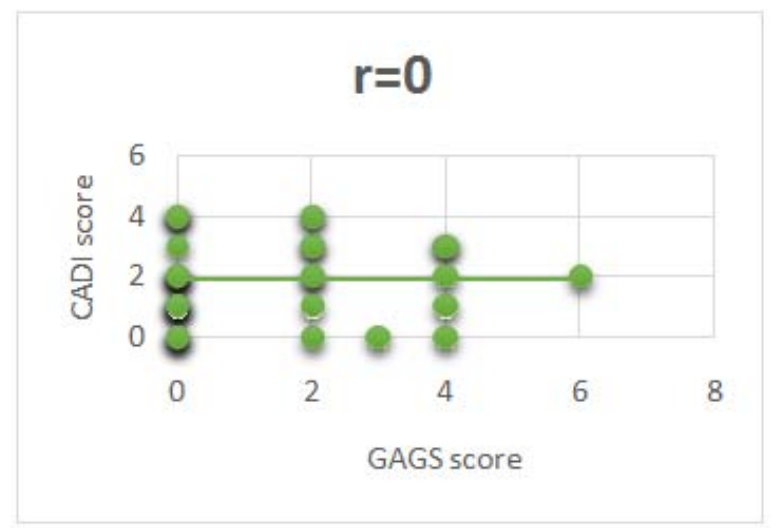

Fig. 3: Grade I acne vulgaris $(n=30), r=$ Correlation coefficient

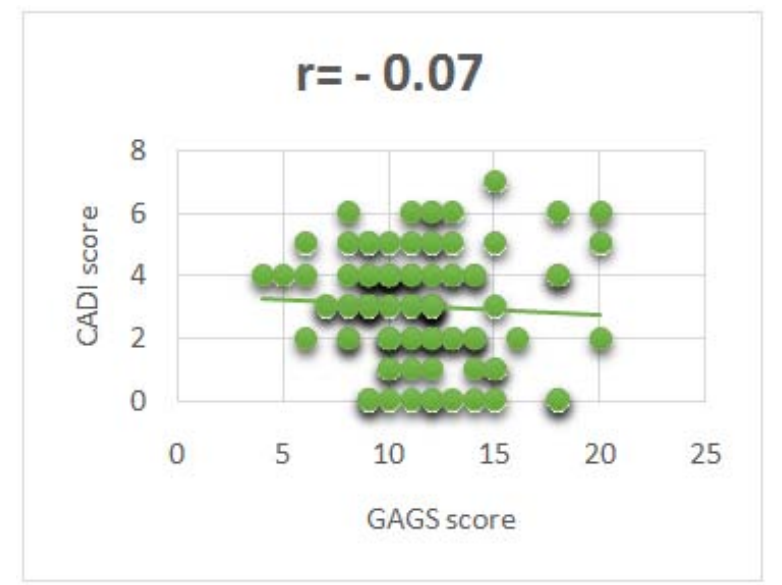

Fig. 4: Grade II acne vulgaris (n=96), r = Correlation coefficient

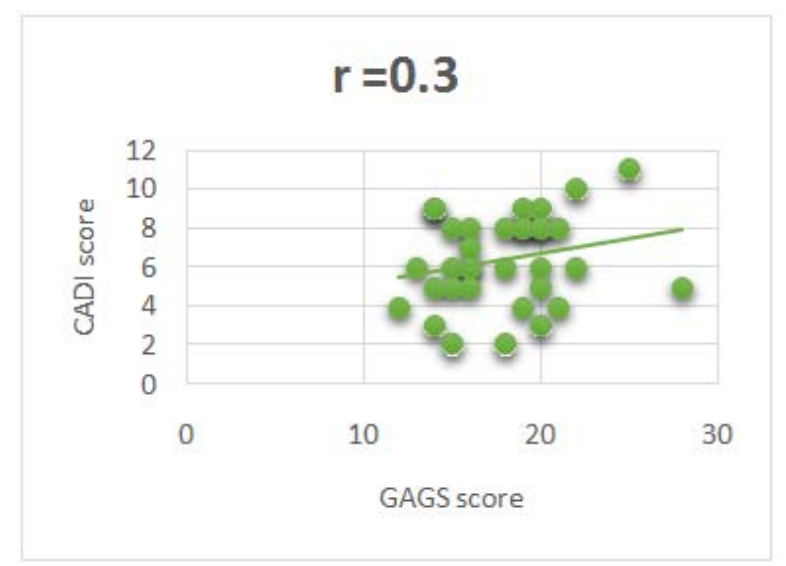

Fig. 5: Grade III acne vulgaris $(\mathrm{n}=34), \mathrm{r}=$ Correlation coefficient

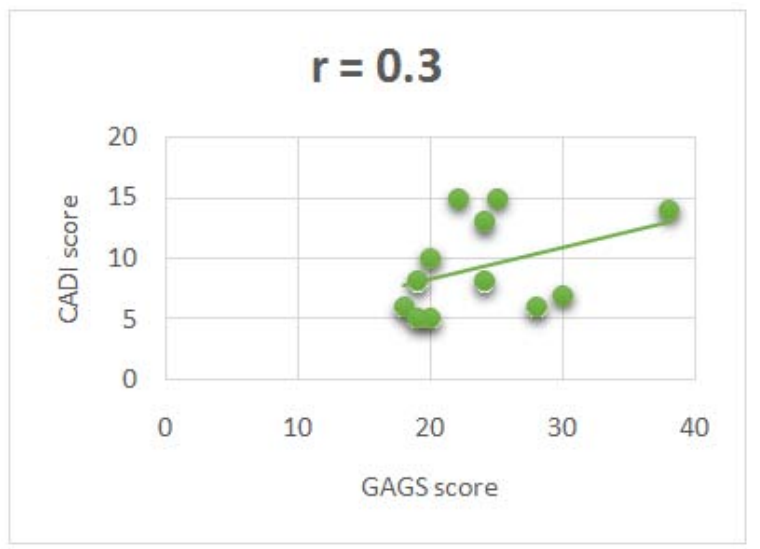

Fig. 6: Grade IV acne vulgaris $(\mathrm{n}=12), \mathrm{r}=$ Correlation coefficient

\section{DISCUSSION}

Acne vulgaris is a common skin disease and its origin is multifactorial. It initially starts as comedones and papules and gradually progress to pustules, cysts and nodules. The pathogenesis in acne include hypersecretion of sebum, androgenic stimulation of sebaceous glands, ductal hyperkeratosis, proliferation of the bacteria Propionibacterium acnes and release of inflammatory mediators like IL-1, etc. [13-15].

Mild to moderate cases responds to topical agents such as retinoic acid, Benzoyl peroxide, salicylic acid and severe resistant forms respond better with oral antibiotics such as tetracycline, azithromycin and oral isotretinoin.

Different grading systems are used to measure the severity of acne. An ideal system for grading acne should be simple, accurate, less expensive and less time-consuming.

There are different methods for measuring the severity of acne vulgaris, which includes simple grading based on clinical examination, lesion counting and other methods such as photography, video microscopy and measurement of sebum production [7].

In this study, we have used the Global Acne Grading System (GAGS). GAGS score was used to evaluate efficacy in all the grades of acne vulgaris. It was observed that the GAGS score was significantly improved in all four grades at the $F / U$ visit $(p<0.05)$ as compared to baseline. Some other systems of grading include the Leed's Technique by Burke et al. [16], Cook et al. [17] used photographic methods to grade acne, Vahlquist et al. [18]graded acne by counting lesions on face, chest and back. Lucchiana et al. [19] and Philips et al. [20] proposed fluorescent photographic methods and polarized light photographic techniques to grade acne.

Acne vulgaris has a tremendous impact on the quality of life of patients. Several studies showed that acne can lead to anxiety, depression, social withdrawal, low self-esteem, especially in teenagers and adolescents [21]. In several subjects affected with severe forms of acne suicidal tendencies were also seen [22]. Different types of the questionnaire are used to measure the impact of acne on an individual's psychosocial health. Acne-specific quality of life questionnaire (Acne-QoL) [23], Acne Quality of Life Scale (AQOL) [23], Dermatological Quality of Life Scale (DQOL) [24], Skindex-29 [25] and Euro QoL 5D [26]are some of them. In this study, we have used the CADI questionnaire developed by Finlay [9] to assess the impact of acne on a person's psychosocial health. It consists of five questions about a person's feelings since the last month, interaction with the opposite gender, social life, skin appearance, avoiding public places and perceived severity of skin disease. It was observed using the CADI questionnaire that the CADI score was significantly reduced in all the four groups $(p<0.05)$ at the end of four weeks compared to baseline in our study.

Attempt was also made to correlate the GAGS score and the CADI score at the follow up visit at $4 \mathrm{w}$ of therapy in all grades of acne 
vulgaris. In Grade I Acne vulgaris, corelation coefficient ( $\mathrm{r}$ ) was 0, which show that there is no correlation between GAGS score and CADI score. In Grade III and IV acne vulgaris, correlation coefficient (r) was 0.3, which shows weak positive correlation between GAGS and CADI score. In Grade II acne vulgaris, correlation coefficient (r) was- 0.07 which shows little negative or no correlation. In none of the groups, correlation was significant ( $\mathrm{p} \geq 0.05)$.

\section{CONCLUSION}

From this study we can conclude that following drug therapy the clinical severity of acne decreased considerably from the first visit at the OPD in all grades of acne patients. We also observe that there was a significant improvement in an individual's social and interpersonal relationships, as was evident from the decrease in the scoring in the CADI questionnaire. Considering the social and psychological consequences of acne vulgaris in an individual, questionnaire-based methods to evaluate the quality of life of patients becomes necessary for better patient management.

\section{ACKNOWLEDGEMENT}

We express our thankfulness to the Department of Dermatology, Gauhati Medical College for allowing us to conduct the study.

\section{FUNDING}

Nil

\section{AUTHORS CONTRIBUTIONS}

The authors have actively participated in the research work and writing the manuscript.

\section{CONFLICTS OF INTERESTS}

The authors declare no conflict of interest

\section{REFERENCES}

1. Burton JL, Cunliffe WJ, Stafford I, Shuster S. The prevalence of acne vulgaris in adolescence. Br J Dermatol. 1971;85(2):11926. doi: 10.1111/j.1365-2133.1971.tb07195.x, PMID 4255129.

2. Kucharska A, Szmurło A, Sinska B. Significance of diet in treated and untreated acne vulgaris. Postepy Dermatol Alergol. 2016;33(2):81-6. doi: 10.5114/ada.2016.59146, PMID 27279815.

3. Bowe WP, Joshi SS, Shalita AR. Diet and acne. J Am Acad Dermatol. 2010;63(1):124-41. doi: 10.1016/j.jaad.2009.07.043, PMID 20338665.

4. Kris-Etherton PM, Taylor DS, Yu-Poth S, Huth P, Moriarty K, Fishell V, Hargrove RL, Zhao G, Etherton TD. Polyunsaturated fatty acids in the food chain in the United States. Am J Clin Nutr. 2000;71(1);Suppl:179S-88S. doi: 10.1093/ajcn/71.1.179S, PMID 10617969.

5. Thiboutot DM, Strauss JS. Diseases of sebaceous glands. In: Freedberg IM, Eisen AZ, Wolff K, Austen KF, Goldsmith LA, Katz SI, editors. Dermatology in general Medicine. 6th ed. Vol. 1. New York: McGraw-Hill; 2003. p. 672-87.

6. Witkowski JA, Parish LC. From other ghosts of the past: acne lesion counting. J Am Acad Dermatol. 1999;40(1):131. doi: 10.1016/s0190-9622(99)70552-9, PMID 9922034.

7. Doshi A, Zaheer A, Stiller MJ. A comparison of current acne grading systems and a proposal of a novel system. Int J Dermatol. 1997;36(6):416-8. doi: 10.1046/j.13654362.1997.00099.x, PMID 9248884.
8. Halvorsen JA, Stern RS, Dalgard F, Thoresen M, Bjertness E, Lien L. Suicidal ideation, mental health problems, and social impairment are increased in adolescents with acne: a population-based study. J Invest Dermatol. 2011;131(2):36370. doi: 10.1038/jid.2010.264, PMID 20844551.

9. Prasad. Acne vulgaris: a review on pathophysiology and treatment. Asian J Pharm Clin Res. 2016;9(4):54-9.

10. Motley RJ, Finlay AY. Practical use of a disability index in the routine management of acne. Clin Exp Dermatol. 1992;17(1):1 3. doi: 10.1111/j.1365-2230.1992.tb02521.x, PMID 1424249.

11. Goulden V, Clark SM, Cunliffe WJ. Post-adolescent acne: a review of clinical features. Br J Dermatol. 1997;136(1):66-70. doi: 10.1046/j.1365-2133.1997.d01-1144.x', PMID 9039297.

12. who.int/medicines/areas/rational _use/en/. [Last accessed on 20 Aug 2021]

13. Cunliffe WJ, Simpson NB. Disorders of sebaceous glands. In: Champion RH, Burton JL, Burns DA, Breathnach SM, editors. Rooks textbook of dermatology. 6th ed. Vol. 3. Oxford: Blackwell Publishing Science; 1998. p. 1927-84.

14. Burton JL, Shuster S. The relationship between seborrhoea and acne vulgaris. $\mathrm{Br} J$ Dermatol. 1971;84(6):600-2. doi: 10.1111/j.1365-2133.1971.tb02553.x, PMID 4254112.

15. James WD, Berger TG, Elston DM. Andrew's diseases of the skin, Clinical. 9th ed. Philadelphia: Saunders. Dermatology; 2000.

16. Burke BM, Cunliffe WJ. The assessment of acne vulgaris-the Leeds technique. Br J Dermatol. 1984;111(1):83-92. doi: 10.1111/j.1365-2133.1984.tb04020.x, PMID 6234917.

17. Cook CH, Centner RL, Michaels SE. An acne grading method using photographic standards. Arch Dermatol. 1979;115(5):571-5, PMID 156006.

18. Michaelson G, Juhlin L, Vahlquist A. Oral zinc sulphate therapy for acne vulgaris. Acta Derm Venereol. 1977;57(4):372. PMID 70937.

19. Lucchina LC, Kollias N, Phillips SB. Quantitative evaluation of non-inflammatory acne with fluroscence photography. J Invest Dermatol. 1994;102:560.

20. Phillips SB, Kollias N, Gillies R, Muccini JA, Drake LA. Polarized light photography enhances visualization of inflammatory lesions of acne vulgaris. J Am Acad Dermatol. 1997;37(6):94852. doi: 10.1016/s0190-9622(97)70070-7, PMID 9418762.

21. Schairer DO, Chouake JS, Nosanchuk JD, Friedman AJ. The potential of nitric oxide-releasing therapies as antimicrobial agents. Virulence. 2012;3(3):271-9. doi: 10.4161/viru.20328, PMID 22546899.

22. Chu TC. Acne and other facial eruptions. Medicine. 1997;25:30-3.

23. Gupta MA, Johnson AM, Gupta AK. The development of an acne quality of life scale: reliability, validity, and relation to subjective acne severity in mild to moderate acne vulgaris. Acta Derm Venereol. 1998;78(6):451-6. doi: 10.1080/000155598442773, PMID 9833047.

24. Morgan M, McCreedy R, Simpson J, Hay RJ. Dermatology quality of life scales--a measure of the impact of skin diseases. Br J Dermatol. 1997;136(2):202-6. PMID 9068732.

25. Chren MM, Lasek RJ, Quinn LM, Mostow EN, Zyzanski SJ. Skindex, a quality-of-life measure for patients with skin disease: reliability, validity, and responsiveness. J Invest Dermatol. 1996;107(5):707-13. doi: 10.1111/15231747.ep12365600, PMID 8875954.

26. Ware JE, Sherbourne CD. The MOS 36-item short-form health survey (SF-36). I. Conceptual framework and item selection. Med Care. 1992;30(6):473-83. doi: 10.1097/00005650199206000-00002. PMID 1593914. 